\title{
Uma Pesquisa-Ação-Intervenção em Saúde Bucal Coletiva: contribuindo para a produção de novas análises
}

\section{A Intervention-Research-Action in Collective Oral Health: contributing to new analyses' production}

\author{
Luciane Maria Pezzato \\ Doutora em Saúde Coletiva. Docente da Faculdade de Odontologia \\ / Centro de Ciências da Vida/ PUC-Campinas. \\ Endereço: Av. John Boyd Dunlop s/n Jad. Ipaussurama, CEP 13060- \\ 904, Campinas, SP, Brasil. \\ E-mail: lupezzato®yahoo.com.br

\section{Solange L'Abbate} \\ Livre Docente. Professora associada do Departamento de Saúde \\ Coletiva da Faculdade de Ciências Médicas da Universidade Esta- \\ dual de Campinas / Unicamp. \\ Endereço: R. Tessália Vieira de Camargo, 126, Caixa Posta 6III, \\ CEPI3083-970, Campinas, SP, Brasil \\ E-mail: slabbate®fcm.unicamp.br
}

Resumo

Este artigo tem como objetivo apresentar a estratégia metodológica produzida e exercitada durante o desenvolvimento de uma pesquisa de doutorado que tomou como quadro teórico-metodológico a abordagem da Análise Institucional na Saúde Coletiva. Pretende, também, contribuir para o debate sobre as abordagens metodológicas que colocam em pauta a relação entre o pesquisador e o ato de pesquisar. Ao longo da investigação, a pesquisaação foi se configurando e se (entre)cruzando com a pesquisa-intervenção, num percurso que estamos denominando pesquisa-ação-intervenção. Desse modo, a pesquisadora, os momentos da pesquisa e da produção teórico-metodológica foram construídos/constituídos ao mesmo tempo, num processo mediatizado pelos saberes e pelos não-saberes dos sujeitos implicados com esta investigação. Podemos dizer que houve dois processos articulados de açãointervenção: um da pesquisadora no e com o grupo, e, outro, dos participantes do grupo, profissionais do Sistema Único de Saúde do município de Campinas em seu cotidiano, na produção do cuidado em Saúde Bucal.

Palavras-chave: Pesquisa Qualitativa; Grupos; Saúde Bucal; Saúde Coletiva; Serviços de Saúde. 


\section{Abstract}

This article describes the methodological strategy created during the research carried out for a doctoral degree, with Institutional Analysis in Collective Health being used as the theoretical and methodological framework. The article is thus meant as a contribution to the debate on methodological approaches to the relationships between researchers and their act of researching. During the investigation, action-research operated as a crossroad between intervention and research, along a path we refer to as intervention-research-action. The research stages and the theoretical-methodological production were constructed concurrently, in a process mediated by the knowledge and questions of the subjects related to this investigation. Knowledge production in the area of oral health care was made through two articulated processes of intervention-action: one of the researcher in and within the group, other of the participants in the group, namely professionals in public health in their everyday life work in oral health care.

Keywords: Qualitative Research; Groups; Oral Health; Collective Health; Health Services.

\section{Introdução}

A pesquisa não nasce, ela irrompe e nos mergulha em seu magma. De certa forma podemos admitir que ela já existia em nós, em um diferente e especial estado contraído, e que já habitava a nuvem virtual e contínua de nossa própria duração, à espera de sua atualização; que a pesquisa enfim, corresponde ao nosso próprio passado, grávido de muitos futuros e devires. (Fonseca e col., 2006, p. 656).

Este artigo é parte de uma tese de doutorado, que, tendo como cenário a rede municipal de saúde de Campinas-SP (Pezzato, 2009), analisou os efeitos e sentidos que uma proposta instituinte provocou nos modos de agir e pensar de diferentes sujeitos atuantes na Saúde Bucal dos serviços de atenção básica. Buscou-se também contribuir para o debate das abordagens metodológicas que colocam em pauta a relação entre o pesquisador e o ato de pesquisar.

O modo como vinha sendo organizado o cuidado em Saúde Bucal, no referido município, foi o que desencadeou a referida pesquisa: a aproximação de quatro cirurgiões dentistas da rede básica à pesquisadora resultou na orientação de uma monografia ${ }^{1}$ que expressava um desejo muito grande dos seus autores $^{2}$ de acompanhar o movimento de mudança que estava ocorrendo nos serviços de saúde do município, de forma a incorporar às ações de Saúde Bucal as diretrizes do novo modelo que estava sendo implantado. Em 2001 teve início uma gestão da Secretaria Municipal de Saúde-SMS que implantou um novo modelo de atenção - o Projeto Paidéia de Saúde da Família. Este se propunha a transformar o modo de produzir saúde no município através da busca de um aumento no coeficiente de autonomia e de auto cuidado das pessoas e da comunidade - o efeito Paidéia (Campos, 2003).

Tais premissas apoiaram-se em alguns pressupostos do Programa Saúde da Família-PSF proposto pelo Ministério da Saúde em 1994² ajustadas ao contexto da rede básica de saúde local, e criaram um

\footnotetext{
1 Nakachima, A. et al. A co-participação do usuário do SUS no seu cuidado em saúde bucal: o conceito da Alta Pactuada. 2004. Monografia (Lato-Sensu). Pontifícia Universidade Católica de Campinas. Campinas-SP, 2004.

2 Três deles exerciam à época, a função de apoiadores distritais da SMS, ou seja, possuíam atribuições pedagógicas, técnicas, analíticas e administrativas junto à gestão das unidades de saúde.

3 Sobre o PSF, consultar: <http://dtr2004.saude.gov.br/dab/atencaobasica.php>. Acesso em 10 abr. og.
} 
modo de operar singular. Este arranjo, apoiado em um conjunto de conceitos serviram como referência aos profissionais na busca de superar certos limites da clínica e dos modos de organizar a produção da saúde, a fim de reorientar"as práticas de saúde, voltando-as para ampliar a capacidade de análise e co-gestão dos Sujeitos" (Campos, 2003, p. 16).

Tal estudo monográfico desenvolveu uma proposta inovadora/instituinte de modificação no modo de produção do cuidado em Saúde Bucal, fortemente instituído nos serviços de atenção básica no SUS-Campinas. Com o intuito de colocar em prática, nos seus cotidianos, as propostas contidas nessa monografia,os participantes constituíram um grupo, do qual participaram também a orientadora e outros profissionais da rede, cujo objetivo era desenvolver um projeto de intervenção em algumas Unidades de Saúde do município. Instaurou-se, portanto, um movimento de repensar a própria prática. Esse movimento instituinte provocou diferentes efeitos e sentidos no cotidiano de alguns cirurgiõesdentistas envolvidos no projeto, resultando numa pesquisa que atuou como dispositivo de análise desse "acontecimento".

De acordo com Baremblitt (2002, p. 134):

Acontecimento é um ato, processo e resultado da atividade afirmativa do acaso. É o momento da aparição do novo absoluto, da diferença e da singularidade. Estes atos, processos e resultados, conseqüências de conexões insólitas que escapam das construções do instituído - organizado, estabelecido, são substrato de transformações de pequeno ou grande porte que revolucionam a História em todos os seus níveis e âmbitos.

Desde o início dessa investigação, percebemos que houve alguns encontros, algumas capturas de múltiplos acontecimentos que configuraram o caminho percorrido; ao mesmo tempo, este caminhar produziu um sentido para esses acontecimentos.

Nessa perspectiva, Aguiar e Rocha (2007, p. 654) entendem que:

Pesquisar é, antes de mais nada, uma atitude que interroga os homens e os fatos em seus processos de constituição, trazendo para o campo de análise as histórias, o caráter transitório e parcial, os recortes que a investigação imprime nas práticas e a forma como produz seus próprios objetos-efeitos.

Entendemos "objetos-efeitos" como acontecimentos únicos, irrepetíveis que, quando produzidos, potencializam fenômenos - "efeitos" - que são circunstanciais, naquilo que está em movimento, naquilo que está sendo processado. Neste sentido, os objetos-efeito foram surgindo no percurso desta investigação, o que gerou aberturas/brechas que possibilitaram o encontro entre a pesquisa-ação e a pesquisa-intervenção.

O arcabouço teórico-metodológico foi constituído a partir dos referenciais da pesquisa-ação, iniciada por Kurt Lewin na década de 40 e posteriormente discutida e re-significada por diferentes autores, e da pesquisa-intervenção proposta pelos analistas institucionais.

Não pretendemos aqui realizar uma revisão exaustiva dessas abordagens e dos debates em torno delas, a fim de "inaugurar uma outra possibilidade de articulação entre teoria e prática, sujeito e objeto nas investigações sociológicas, psicológicas, educacionais, organizacionais" (Rocha e Aguiar, 2003, p. 2). O que propomos é estimular um diálogo ao explicitar a singularidade da combinação das duas abordagens, quando se tem como objeto a Saúde Bucal Coletiva. Em última análise, busca-se articular pesquisa, reflexão, ação, teoria, prática, intervenção, clínica, política, sujeitos, desejos..., demarcando uma forte interrelação entre ambas. Isto nos autorizou a denominar esta estratégia metodológica de "pesquisa-ação-intervenção". Entendemos que, "neste contexto onde se atravessam clínica e política, pesquisa e ação, a palavra intervenção se junta à pesquisa não para substituir a ação, mas para produzir outra relação entre teoria e prática, assim como entre sujeito e objeto" (Passos e Barros, 2000, p. 73).

Assim, torna-se inoportuno qualquer referência sobre uma possível neutralidade dos sujeitos envolvidos nesta pesquisa, uma vez que estamos situando/compreendendo este processo no campo da Análise Institucional/AI, que segundo L'Abbate (2005, p. 237) “[...] nasceu da articulação entre intervenção e pesquisa, entre teoria e prática e tem por objetivo compreender uma determinada realidade social e organizacional, a partir dos discursos e práticas dos seus sujeitos". 
Para capturar as várias nuances e desafios presentes, tendo em vista o objeto deste estudo, optamos pela técnica do diário, como ferramenta de ação-intervenção para identificar os processos em curso, e, sobretudo, para analisar as implicações dos sujeitos desta pesquisa, incluindo as da pesquisadora.

É neste contexto, portanto, que se inscreve este artigo que tem como objetivo apresentar a estratégia metodológica produzida e exercitada durante o desenvolvimento da pesquisa de doutorado já referida.

\section{Procedimentos Teórico-} metodológicos da Investigação:

\section{a pesquisa-ação e a pesquisa- intervenção}

Iniciaremos pela Pesquisa-ação. Não existe uma forma única de pesquisa-ação; as diversas tipologias desse tipo de metodologia revelam, segundo El Andaloussi (2004, p.94), "a multiplicidade das representações em torno do conceito, de sua riqueza e de seu caráter promissor. As definições são diferentes, variam segundo o ponto de vista epistemológico, ideológico e metodológico".

Tripp (2005, p.445) parte do pressuposto de que "não há certeza sobre quem inventou a pesquisaação", pois as pessoas sempre procuraram compreender e investigar a própria prática com o objetivo de melhorá-la; neste sentido, o autor cita os trabalhos “interraciais" de John Collier na Índia, refere o conceito de reflexão utilizado por John Dewey, publicado em 1933 e reporta-se, inclusive, aos antigos empiristas gregos, que provavelmente pesquisavam suas próprias ações. Todavia, Tripp atribui a Lewin, na década de 40, o mérito de ter sido o primeiro a publicar um trabalho empregando o termo.

De acordo com Barros (2007, p. 228), a pesquisaação sistematizada por Kurt Lewin,

[...] foi um importante instrumento na tentativa de articular teoria e prática, teoria e ação. [...] Visava Lewin, em suas pesquisas, ao alívio das preocupações das pessoas em situação problemática, mas, simultaneamente, ao desenvolvimento das ciências sociais. Foi assim que a pesquisa-ação ganhou o terreno da sociologia, bem como o da psicologia social, da educação, do trabalho, aplicando ao campo microssocial modelos derivados das ciências fisioquímicas.

Barbier (2002) faz uma crítica à pesquisa-ação lewiniana com relação ao lugar ocupado pelo pesquisador. Ele reconhece as diferenças marcantes que esta apresenta em relação às pesquisas sociológicas clássicas, que pressupunham um pesquisador neutro, externo ao campo de investigação; no entanto, ressalta o fato de que o pesquisador, mesmo estando incluído no campo que investiga, continua sendo um "entrevistador", um sujeito não implicado no processo, portanto distante do "objeto" em análise.

Ainda que seus trabalhos tenham sido alvo de muitas críticas (El Andaloussi, 2004), não há como negar a contribuição de Lewin, seus colaboradores e discípulos para o desenvolvimento das ciências humanas.. Barbier (2002, p. 57) procura integrar tais críticas referindo-se a uma "nova pesquisa-ação", que se abre para uma "psicossociologia clínica e para uma etnografia de campo", em que destaca os educadores australianos Wilfred Carr e Stephen Kemmis.

Na década de 60 surgiram vários movimentos de pesquisa-ação com diferentes tendências, tanto no campo da sociologia como no da educação. $\mathrm{Na}$ educação, podemos destacar as contribuições de John Elliott, que se dedicou a pesquisar a prática docente "como meio de produzir conhecimento sobre os problemas vividos pelo profissional, com vistas a atingir uma melhora da situação, de si mesmo e da coletividade”. (Pereira, 1998, p. 154). Na Saúde Coletiva tem sido mais utilizada a pesquisa-ação de caráter sociológico proposta por Thiollent (2005), com ênfase em análises dos aspectos estruturais da realidade vinculadas a projetos de ação social, com vistas à solução de problemas coletivos.

Concordamos com Barbier (2002, p. 117) em sua síntese do que vem a ser a pesquisa-ação:

[...] o espírito mesmo da pesquisa-ação consiste em uma abordagem em espiral que a todas utiliza. Significa que todo avanço em pesquisa-ação implica o efeito recursivo em função de uma reflexão permanente sobre a ação. [...] Nada de pesquisa sem ação, nada de ação sem pesquisa, como dizia Lewin. [...] Assim, na ação, o pesquisador passa e repassa seu 
olhar sobre o "objeto", isto é, sobre o que vai em direção ao fim de um processo realizando uma ação de mudança permanente. Seu objeto constantemente lhe escapa, arrastado pelo fluxo da vida.

No limite deste artigo, não pretendemos fazer uma exaustiva discussão sobre as características e possibilidades de utilização da pesquisa-ação nos estudos de abordagem qualitativa. Conforme exposto anteriormente, existem diferentes concepções desta modalidade de investigação, podendo, o pesquisador, seguir diferentes perspectivas como também, referenciais teóricos: Barbier, Thiollent, Elliot, Car e Kemmis. Concordamos com El Andaloussi, (2004, p.94) quando reforça que "é importante lembrar que a pesquisa-ação é obra comum do pesquisador e dos profissionais que agem com uma démarche peculiar e que têm, em conjunto, um projeto de mudança social e de produção de conhecimento."

Para abordar a temática da pesquisa-intervenção é importante referir alguns conceitos da Análise Institucional-AI, movimento que surgiu na França nos anos 6o e foi introduzido no Brasil a partir de 1970 (Rodrigues e Barros, 2003; L'Abbate, 2003). De acordo com Lourau (2007, p. 13-14), este movimento pretende trabalhar com a contradição, seguindo uma lógica dialética. "A Análise Institucional não esconde que é política, porém tampouco oculta que em sua 'política' está, como princípio, o conceito de autogestão.”

Ao propor a disciplina/movimento/corrente da AI, René Lourau, fez uma verdadeira arqueologia do conceito de instituição em diversas disciplinas das ciências humanas e sociais, concluindo que nesses vários campos de saber, este conceito restringia-se ao caráter mais formalizado e estático das instituições. Convicto de que a instituição não pode ser reduzida a esta dimensão, Lourau desenvolveu um conceito dialético de instituição, apoiado em Castoriadis e em Hegel (Lourau, 1975, p. 19-143).

Em relação à Castoriadis, ressalte-se "a noção de auto-alteração, comum a toda sociedade, mediante a qual toda instituição social é o resultado de um movimento dialético contínuo entre instituído- instituinte" (L'Abbate, 2005, p. 238).

Inspirado na lógica hegeliana4, Lourau (1975), define instituição como um movimento dinâmico e dialético, resultado de três momentos; o instituído, o instituinte e a institucionalização. 0 momento do instituído, do que está posto, estabelecido, ou seja, as normas, as leis, o que o autor chamou de universal. O momento do instituinte, que, por seu turno, exprime a particularidade, a negação do instituído, do universal, "a contestação, colocação em questão do instituído pelo projeto do que ainda não é”, mas pode vir a ser. (Ardoino e Lourau, 2003, p. 25).

O resultado da relação entre estes dois momentos - instituído e instituinte - é a institucionalização, o momento da singularidade, ou seja, "o equilíbrio metaestável, em perpétuo devir, e não, 'síntese' definitiva..." Isto possibilitou a estes autores definirem instituição como:

[...] um objeto virtual, produzido pela análise, que a elabora ao mesmo tempo em que a interpreta, muito mais do que um objeto real. [...] A instituição é imaterial. Jamais é diretamente apreensível. Só se pode apreendê-la por intermédio da materialidade da organização. Ainda assim, é necessário que um instrumental analítico apropriado permita reconhecê-la em sua especificidade, descolando-a da organização com a qual, de outra forma, ela se confundiria. (Ibidem, p. 17-18).

Tal definição nos permite considerar a Saúde Bucal como instituição fortemente instituída, porém plena de contradições. Contêm em si possibilidades apontadas pela Saúde Coletiva de transformar alguns de seus pressupostos ao compreendê-la de forma integral e integrada no contexto de vida das pessoas, contrapondo-se à Odontologia hegemônica centrada no elemento dental e em suas "técnicas pastorianas" de higienização. Assim como apontado por Narvai (1994) quando afirma que a expressão Saúde Bucal se propõe extrapolar os estreitos limites daquilo que é meramente conhecido como "odontológico". Ou ainda, como afirmaram Botazzo e colaboradores (1988, p.18): “a medida que a odontologia vai se tornando cada vez 'mais integral', vai também

\footnotetext{
4 "A lógica hegeliana distingue, na análise de qualquer conceito, três momentos que, articulando-se, definem a dialética: momentos da universalidade, da singularidade e da particularidade. A dialética obriga a que não nos contentemos com a oposição dualista entre interesses particulares e interesse geral" (Lourau, 2004, p.49).
} 
se tornando cada vez 'menos odontologia'..."

Neste sentido, o "vir a ser" da Saúde Bucal pode, ainda, ser ampliado, apoiando-se na noção de Bucalidade que, segundo Botazzo (2000), constitui-se dos sentidos da boca humana onde ocorre a manducação ("o consumo que a boca realiza"), a linguagem e o erotismo.

[...] bucalidade vem a ser a condição de possibilidade para a superação das práticas odonto-centradas pelo movimento de a um só tempo focar a integralidade corpórea - o corpo do sujeito por inteiro - e então esta clínica ampliada terá de levar em conta a fisiologia do lugar (seu meio interno e sua normatividade), e depois a sensibilidade das vísceras da boca e sua ligação com os modos de existir do próprio homem. (Botazzo, 2006, p. 40-41).

O conceito de instituição, exposto anteriormente, adquiriu concretude quando Lourau propôs um modelo de intervenção denominado Socioanálise, inspirado em outras formas de intervenção mais utilizadas à época (anos 50 e 60), tais como a psicoterapia e a pedagogia institucionais e a psicossociologia, como também, na sua própria experiência em realizar intervenções em grupos e instituições ${ }^{5}$. Tal proposta apoiava-se em alguns princípios ou "regras": análise da encomenda e da demanda, a auto-gestão do grupo, a regra do "tudo dizer”, a elucidação da transversalidade, a análise das implicações, a explicitação dos analisadores e a restituição (L’Abbate, 2005). Lourau (2007, p. 28) ressalta que estes conceitos não possuem "uma ordem lógica, estando sempre em relação dialética uns com os outros".

Embora elaborados na constituição da socioanálise, tais princípios podem ser aplicados em outras formas de intervenção como é o caso desta pesquisa, pois, em síntese, a pesquisa intervenção visa:

[...] interrogar os diversos sentidos cristalizados nas instituições. Trata-se de produzir evidências que visibilizem o jogo de interesses e de poder encontrados no campo de investigação. Sua metodologia está baseada, portanto, numa argüição que possibilita desmanchar os territórios constituídos e convoca a criação de outras instituições. É claro que a própria noção de instituição é modificada, já que, ao não ser identificada à de estabelecimento, remete ao processo de produção constante de modos de legitimação das práticas sociais. (Passos e Barros, 200o, p. 73).

Porém, alguns autores colocam em pauta um debate sobre estas duas abordagens. Aguiar e Rocha (2007) apontam uma heterogeneidade de tendências de pesquisas denominadas participativas e pontuam que a pesquisa-ação e a pesquisa-intervenção estão incluídas neste grupo, pois em ambas,

[...] o sujeito do conhecimento se produz em meio às práticas sócio-históricas, ou seja, o conhecimento enquanto produção e o sujeito inscrito nesse processo se fazem em condições determinadas, o que torna imprópria qualquer alusão acerca de uma possível neutralidade que norteia as práticas de pesquisa. (p. 650).

Entretanto, as autoras enfatizam que a pesquisaintervenção, "enquanto proposta de atuação (trans) formadora, [...] aprofunda a ruptura com os enfoques tradicionais e amplia as bases teórico-metodológicas das pesquisas participativas". (ibidem, p. 655). Afirmam, ainda, que o pensamento institucionalista (francês e argentino) vem re-significando a proposta clássica de pesquisa-ação de Kurt Lewin, em que a gênese social precede a gênese teórica e metodológica.

[...] trata-se, agora, não de uma metodologia com justificativas epistemológicas, e sim, de um dispositivo de intervenção no qual se afirme o ato político que toda investigação constitui. Isso porque, na pesquisa-intervenção, acentua-se todo o tempo o vínculo entre a gênese teórica e a gênese social dos conceitos. (ibidem, p. 655).

Assim, a produção do conhecimento e de práticas na pesquisa-intervenção se dão num mesmo movimento.

Paulon (2005, p. 21) afirma que a pesquisa-intervenção, "ao operar no plano dos acontecimentos, deve guardar sempre a possibilidade do ineditismo da experiência humana, e o pesquisador a disposição para acompanhá-la e surpreender-se com ela”. Neste sentido, o pesquisador não se pretende agente

5 Em grande parte, com parceria de Georges Lapassade (Lourau, 1975, p.289). 
de mudança, mas sim produtor de novos sentidos, novas intercessões.

$\mathrm{Na}$ intervenção socioanalítica ${ }^{6}$, "o pesquisador é, ao mesmo tempo, técnico e praticante” (Lourau, 2007 , p. 28), constituindo-se no movimento do processo de pesquisar, sendo ao mesmo tempo pesquisador e pesquisado, sujeito e objeto de conhecimento (Barros, 2007, p. 232).

Este debate entre a pesquisa-ação e a pesquisaintervenção fundamenta-se nos pressupostos da pesquisa-ação lewiniana. No entanto, quando nos aproximamos das novas abordagens de pesquisaação, percebemos alguns pontos de intersecção entre essas abordagens de pesquisa. É o caso da pesquisaação que propõe uma relação horizontalizada de sujeitos, em que não há neutralidade no ato de pesquisar, que se insere numa perspectiva de construção de conhecimentos e saberes compartilhados, conforme apontado por Pereira (1998, p. 163-4). Esta autora, fundamentada em Elliot, diz o seguinte: "Do ponto de vista metodológico, a pesquisa-ação se concebe de modo amplo e flexível, não se modelando a priori, mas se desenhando na relação entre os elementos implicados nela. [...] para superar os binômios: teoria-prática, educador-investigador".

Já Monceau (2005, p. 469) traça um paralelo entre pesquisa-ação e pesquisa-intervenção com a finalidade de demonstrar que a "designação pesquisaação não passa de uma possibilidade entre outras de qualificar, na instituição científica, um gênero que possui especificidades que é importante precisar", e propõe outro campo de pesquisa em elaboração, a Socioclínica.

O que está em pauta, portanto, é a natureza da relação sujeito e objeto nas ciências humanas e sociais, e é neste terreno que o conceito de implicação se insere e demarca sua vinculação teórica.

Para Lourau (2004b), é na implicação do pesquisador/analista com sua pesquisa/produção que estará demarcada a posição frente à neutralidade dos pesquisadores em ciências sociais. Para o autor, "todas as ciências estão baseadas na noção de impli- cação ou desimplicação", pois é o conjunto de condições de uma pesquisa que possibilitará a implicação ou não do pesquisador, determinando assim, a qual ciência estamos nos referindo (Lourau, 2007, p. 9). Todavia, "a Análise Institucional tenta, timidamente, ser um pouco mais científica. Quer dizer, tenta não fazer um isolamento entre o ato de pesquisar e o momento em que a pesquisa acontece na construção do conhecimento" (Lourau, 2007, p. 16).

A noção de implicação constitui-se de um conjunto de relações,

[...] que o intelectual recusa, conscientemente ou não de analisar na sua prática, quer se trate de relações com seus objetos de estudo, com a instituição cultural, com seu meio familiar, bem como a outras dimensões, como o dinheiro, o poder, a libido, e em geral com a sociedade da qual ele faz parte. (Lourau, 1981, p. 24)

Pesquisa-ação e/ou pesquisa intervenção? Entendemos que ambas são modos de abordagem da micropolítica presente no cotidiano dos serviços de saúde e que o debate em torno da necessidade de demarcar, ou não, os espaços/territórios de cada uma delas encontra-se aberto. Cabe ao pesquisador interessado em tais abordagens capturar o que está em consonância com os propósitos da investigação que pretende produzir.

$\mathrm{Na}$ investigação que deu origem a este artigo, colocamos em análise as práticas cotidianas de um grupo de profissionais da Saúde Bucal que atuam na rede básica de Campinas, (entre)cruzando com/na pesquisa-intervenção, configurando o que estamos denominando: uma pesquisa-ação-intervenção.

\section{O Percurso desta Pesquisa-Ação- Intervenção}

A forma de atuar, tanto da pesquisa-ação, quanto da pesquisa-intervenção, depende de uma forte interação entre todos os participantes do trabalho, e, neste caso, não poderia ser diferente.

6 Observa-se que o tipo de intervenção proposta por Lourau foi, basicamente, o da socioanálise, sendo que outros autores, que também se apóiam na AI francesa, entendem Intervenção de forma mais ampla (SPAGNOL, C. A trama de conflitos vivenciada pela equipe de enfermagem no contexto da instituição hospitalar: como explicitar seus nós? 20o6. Tese (Doutorado em Saúde Coletiva) - Faculdade de Ciências Médicas - UNICAMP. Campinas-SP. 2006; Monceau, 2005; Paulon, 2005; Barros, 2007; Rocha e Aguiar, 2003). 
Mobilizados pelas demandas que emergiram da interrogação das próprias condições de produção do cuidado em Saúde Bucal nos seus diferentes espaços de atuação, os autores e a orientadora da monografia, referida anteriormente, decidiram formar um grupo para refletir e discutir a proposta em pauta ${ }^{7}$, a fim de construir um projeto de intervenção na rede básica. Tal proposta configurou-se como uma oferta, gerando uma série de demandas: definir quem iria participar além dos que já estavam envolvidos com a monografia, buscar as condições necessárias à realização dos encontros, levar a proposta para o gestor municipal, entre outras. Esse conjunto de demandas gerou uma encomenda feita pela orientadora que se propôs a acompanhar o trabalho de reflexão do grupo, sendo que este movimento constituiria sua pesquisa de doutorado. No momento em que esta proposta foi aceita configurou-se um novo contexto, tanto para o grupo como para cada um individualmente. A orientadora passou a ocupar o lugar de pesquisadora e os integrantes do grupo pesquisadores da própria prática ${ }^{8}$.

Para Lourau, (2007, p. 33) toda encomenda tem origem num conjunto de demandas existentes anteriormente, pois "há demandas que preexistem ao trabalho socioanalítico".

Numa socioanálise clássica, a encomenda é o pedido oficial feito por parte de um grupo ou organização para que a intervenção ocorra (Lourau, 1975; Hess e Savoye, 1993). Nesse caso, tal encomenda não seguiu essa regra, porém consideramos que alguns princípios socioanalíticos estavam presentes. Estava presente também a condição necessária antecedente da pesquisa-ação, que segundo Pereira (1998, p. 167), "é que os práticos sintam a necessidade de iniciar mudanças, de inovar”.

A partir daí, as demandas foram se modificando influenciadas pela análise das implicações dos participantes tanto em relação aos seus espaços de trabalho como à própria investigação. Por isso a produção das demandas constituiu-se também em objeto de análise.
Este acontecimento fez fluir uma série de movimentos instituintes na forma "tradicional"/ instituída de operar da clínica odontológica em algumas unidades de saúde, colocando em análise concepções, saberes, relações estabelecidas entre os profissionais, os usuários, os gestores e os conselhos locais e municipal de saúde. Tal movimento provocou rupturas no instituído, naquilo que estava “consolidado" - seja nas ações específicas, seja nas ações "menos odontológicas" -, naquilo que estava historicamente posto para o cirurgião-dentista com relação à Saúde Coletiva.

Neste sentido, a proposta que estava em pauta no grupo, na tentativa de ser aplicada em algumas unidades, funcionou como um analisador, revelando dimensões relevantes e significativas do processo de trabalho das equipes, bem como da própria gestão municipal de saúde, dimensões estas que se encontravam ocultas ou, em certas situações, um tanto camufladas.

Em sua composição, o grupo contou com a representação de diferentes instâncias: gestão, área meio e área fim da SMS/Campinas e a Universidade. Manteve uma agenda durante um período compreendido de novembro de 2004 a setembro de 2008 , totalizando 21 encontros, que, em princípio, seriam mensais, o que nem sempre foi possível. No primeiro ano, doze cirurgiões dentistas estiveram envolvidos com as propostas do grupo, porém a participação de alguns foi mais pontual.

Este "pequeno grupo" era nosso "dispositivo de intervenção". As discussões coletivas traziam os desejos, as angústias, demarcavam-se as relações de poder, de lugares ocupados e não ocupados pelos participantes, revelando, assim, suas implicações e pertencimentos, situando-nos acerca das respostas da rede à nossa proposta de ação-intervenção, que nem sempre era acolhida ou mesmo compreendida.

Neste sentido concordamos com Barros (2007) quando afirma que o pequeno grupo é um dispositivo extraordinário de análise, pois é a partir dele que se promove a fala, o vínculo, entre os integrantes do grupo.

\footnotetext{
7 Denominada “Alta Pactuada em Saúde Bucal”, propõe enfatizar o lugar do usuário na atenção em Saúde Bucal, considerando-o sujeito capaz de autonomia, exercida de forma compartilhada com o profissional da área.

8 Deste modo, o projeto de doutorado foi encaminhado e aprovado pelo Comitê de Ética e Pesquisa da FCM/Unicamp e os participantes do grupo assinaram o Termo de Consentimento Livre e Esclarecido.
} 
Para Lourau (1979, p. 23), o pequeno grupo é um dispositivo,

[...] que nada tem de desprezível, foi objecto de uma subversão a partir do momento em que, rompendo com instituído da "dinâmica de grupo", Lapassade e os seus primeiros "clientes" efectuaram a análise da encomenda e do pedido de intervenção (ou de formação), fazendo assim eclodir o campo de análise fora das famosas "fronteiras de grupo".

O movimento interno do grupo é sempre muito complexo, por isso procuramos (sentimos que era geral esse pressuposto) manter a autonomia do espaço de cada um dos participantes, permitindo, assim, instaurar uma autogestão do grupo. Todavia, não tivemos muito êxito nesta empreitada. Conforme afirmou Lourau (2007, p.14), referindo-se às contradições existentes na Análise Institucional:

A autogestão que existe, a que tem podido existir, acontece dentro de uma contradição total, já que a vida cotidiana, a minha e também a de vocês ${ }^{9}$, se passa no terreno da heterogestão. [...] Cotidianamente preferimos não nos colocar muitos problemas e, "permitimos" que se dê a heterogestão, "confiamos" a "autogestão" a outras pessoas. [...] Amamos nossa "alienação".

Para este autor, a autogestão sempre é uma primeira opção no processo socioanalítico. As pessoas vivem no mundo da heterogestão em todos os lugares, ou seja, somos "geridos por outrem", e tal fato é encarado como algo natural. Esta naturalização da heterogestão não apenas nos aliena como nos priva da autonomia, da liberdade. Como dizia Lourau, "é muito doloroso a análise de nossas implicações; ou melhor, a análise dos 'lugares' que ocupamos, ativamente, neste mundo". É mais cômodo deixar que pensem, decidam por nós, pois deste modo "parece" que tiramos de nós o peso da responsabilidade, como se nada disso refletisse, em algum momento, de alguma maneira, em nossas vidas (Lourau, 2007, p. 14).

Isso também aconteceu no grupo, pelo conjunto de condições estabelecidas entre os integrantes que acabaram por confiar a gestão/coordenação do grupo à pesquisadora. Porém, não se instalou uma heterogestão, uma alienação real, conforme definida por Campos (2005, p. 27) como "separação, concreta e cotidiana, dos produtores da gestão dos meios de produção e do resultado do seu próprio trabalho", pois estávamos construindo um espaço coletivo em busca do fortalecimento de cada um dos sujeitos envolvidos. Melhor seria dizer que houve sempre um processo de co-gestão, pois, apesar de certos momentos de alienação, cada participante foi agregando outros saberes aos já existentes e às suas experiências, de forma a construir um projeto, ao mesmo tempo coletivo e individual, todos procurando manter o caráter instituinte da proposta.

O dispositivo grupo foi criado como espaço de diálogo e discussão dos acontecimentos produzidos nas experienciações da proposta instituinte em pauta nos encontros, oscilando entre ser "grupo sujeito" e ser "grupo sujeitado" (Guattari, 1987). Ou seja, os movimentos gerados com e entre os sujeitos membros do grupo fizeram emergir seu protagonismo, como também sua alienação. A ação da transversalidade veiculada possibilitou encontros e desencontros de instituições, de saberes e práticas presentes no vivido de cada um desses sujeitos, fazendo emergir seus desejos no agenciamento de forças heterogêneas, deflagrando efeitos instituintes e "desformando" os cotidianos desses sujeitos.

Como ferramenta desta ação-intervenção utilizamos a técnica do Diário, para o registro de todo o processo, em três diferentes tipologias: o Diário Institucional-DI e o Diário de Momentos propostos por Hess $(1998 ;$ 2006) e o Diário de Pesquisa de Lourau (1988; 2004c).

O Diário Institucional foi proposto para que cada um dos integrantes registrasse, individualmente, os acontecimentos mais marcantes ao longo do período em que estivesse envolvido com a construção do seu projeto de intervenção e com a pesquisa. Tivemos quatro integrantes do grupo que produziram um Diário Institucional de forma mais sistemática. 0 que permitiu a cada participante trazer à tona suas próprias reflexões, possibilitando inicialmente, sua análise individual a respeito da sua prática de ação-intervenção em seu cotidiano de trabalho, e, num segundo momento, compartilhar tais idéias/

9 Como este texto é o registro fiel de exposições e diálogos que Lourau realizou na UERJ em 1993, às vezes o tom é coloquial. 
ponderações com os demais participantes ${ }^{10}$.Tal movimento permitiu um rico e altamente significativo processo de troca de conhecimentos, de novos saberes e de experiências entre todos os membros do grupo, o que certamente contribuiu para alimentar a motivação dos profissionais no seu esforço de criar e inovar.

Isto porque, os sujeitos possuíam um objetivo comum, motivados pelo desejo de repensar sua açãointervenção. Participavam do grupo, procurando encontrar respostas, pistas para potencializar sua ação-intervenção e consequentemente modificar a realidade do seu cotidiano. Com isso, no decorrer dos encontros, os sujeitos traziam suas propostas, suas ações, suas angústias, seus desejos, suas conquistas, assim como suas dificuldades, possibilitando/ produzindo/construindo um espaço de reflexãoação-intervenção.

Cada uma das "falas" se juntava às outras "falas" que iam adquirindo forma, conformando/deformando/re-conformando os saberes pré-existentes em cada um dos presentes naquele encontro. Este movimento gerava uma reflexão permanente sobre as ações-intervenções dos participantes, pois, quando retornavam para seus "lugares" após os encontros, voltavam "tocados" pelos conteúdos/ saberes destas discussões, as "falas" ecoavam em seus pensamentos.

O Diário de Momentos foi produzido a partir dos registros dos encontros, trazendo discussões, propostas, dúvidas, enfim, os acontecimentos gerados naqueles momentos. Esses registros eram enviados para todos após cada encontro, mesmo para os ausentes, via internet.

Paralelamente, durante todo o tempo que durou a investigação, a pesquisadora produziu um Diário de Pesquisa. Segundo Lourau, (2007, p. 51) "tal técnica não se refere especificamente à pesquisa, mas ao processo do pesquisar".

Em setembro de 2007, ocorreu o último encontro do grupo, justamente quando percebemos que alguns acontecimentos institucionais modificaram o seu percurso. Acompanhamos este movimento e só nos reunimos para apresentar ao grupo as análises que estávamos fazendo dos registros produzidos. Dizen- do de outro modo, propusemos fazer uma restituição "pessoal, implicada e posta" das análises produzidas até aquele momento, antes de terminar a pesquisa, "como um procedimento real e necessário do ato de pesquisar (intervir)" (Lourau, 2007, p. 55).

Segundo Lourau (2007, p. 56), a restituição é um dispositivo que possibilita "considerar a pesquisa para além dos limites de sua redação final; ou melhor, de sua transformação em mercadoria cultural para servir unicamente ao pesquisador e à academia”. Como dispositivo socioanalítico, produz alguns efeitos no sentido de que imprime um "status" de pesquisador aos sujeitos implicados, tornando-os uma espécie de "pesquisador coletivo", como também efetiva "a socialização da pesquisa". Porém, faz-se necessário que "o material restituído pelos socioanalistas tenha relação com a análise de suas próprias implicações, obviamente, na situação de intervenção" (Lourau, 2007). Ou seja, a restituição "consiste em se centrar numa tarefa - a análise coletiva da situação presente, no presente - em função das diversas implicações de cada um com e na situação" (Lorau, 2007, p. 64).

A restituição é mais um denominador comum entre a socioanálise e a pesquisa-ação, deste modo, ela não poderia deixar de acontecer.

Sendo a restituição um movimento para retomar os acontecimentos, em geral excluídos, ela trouxe à tona sentimentos de alegria pelos bons encontros, dos momentos de crescimento coletivo e individual. Momentos de saudades, visto que o grupo se autodissolveu.

Inspirada neste referencial teórico-metodológico, cuja proposta é desmanchar os territórios constituídos e convocar "a criação de outras instituições" (Barros, 2007, p. 231), podemos afirmar que o movimento instituinte gerado pelos integrantes do grupo explicitou, nesta restituição, suas singularidades, seus momentos, e suas vivências/experiências na busca de criar outras institucionalizações para o seu cotidiano na Saúde Bucal (Coletiva). Como afirmou Lourau (2004a, p. 68) "As instituições formam a trama social que une e atravessa os indivíduos, os quais, por meio de sua práxis, mantêm ditas instituições e criam outras novas (instituintes).” 
A restituição foi um acontecimento na medida em que pudemos compreender o movimento instituinte gerado pelo grupo nos diferentes cotidianos de cada um dos sujeitos implicados.

\section{Considerações Finais}

O útil ou necessário para a ética, a pesquisa e a ética da pesquisa não é a implicação - sempre presente em nossas adesões e rechaços, referências e não referências, participações e não participações, sobremotivações e desmotivações, investimentos e desinvestimentos libidinais... -, mas a análise dessa implicação. (grifo das autoras) (Lourau, 2004b, p. 190).

A experiência de acompanhar um grupo e seus sujeitos dispostos a refletir com e sobre o modo de produção do cuidado em saúde bucal em seus cotidianos, bem como registrar em palavras essa experiência, tendo como referencial teórico-metodológico a Análise Institucional, possibilitou a produção e o exercício de uma estratégia metodológica que tomou do fluxo de acontecimentos, possibilidades da produção de análises.

Com o intuito de articular ação, intervenção e pesquisa, teoria e prática, a referida proposta foi debatida, modificada, aplicada, debatida novamente, reelaborada, enfim, gerou algumas análises reveladoras sobre o modo de organizar, gerir, intervir e pensar o cuidado em Saúde Bucal no cotidiano de onze cirurgiões dentistas do serviço de Saúde Bucal do SUS - Campinas. Sendo que, para cada um deles, a intensidade de sua implicação se deu de forma singular.

Deste modo, a pesquisadora, os momentos da pesquisa e da produção teórico-metodológica foram construídos/constituídos ao mesmo tempo, num processo mediatizado pelos saberes e pelos não-saberes dos sujeitos implicados com e nesta ação-intervenção (Lourau, 1975).

Não apresentamos um projeto fechado a priori, os acontecimentos foram se processando em consonância com as reflexões-ações-intervenções geradas no cotidiano de cada um, em seus espaços-territórios de atuação, o que possibilitou nos surpreender com os acontecimentos.
Podemos dizer que houve dois processos de açãointervenção: um da pesquisadora no e com o grupo, e, outro, dos participantes do grupo em seus cotidianos. Como, também, alguns integrantes do grupo se propuseram a refletir sobre suas próprias ações e registrar esses acontecimentos, sendo, também pesquisadores em relação com o ato de pesquisar. A produção das diferentes tipologias de Diário potencializou a compreensão desta ação-intervenção.

O grupo foi um dispositivo utilizado como espaço protegido para o "livre dizer", em que os sujeitos traziam seus incômodos produzidos no cotidiano dos serviços de saúde, como também, dificuldades e novidades pessoais e profissionais no sentido de compartilhar o vivido. Tais efeitos evidenciaram que o processo de produção do trabalho em saúde vai além do intelectual (cérebro) e manual (corpo), ele perpassa também nossa afetividade, nossa vida.

Este modo de produzir/pesquisar favoreceu/ possibilitou o encontro entre os dados subjetivos e objetivos que estiveram em movimento nesta pesquisa-ação-intervenção, colocando em evidência as implicações dos sujeitos como produtores de saberes, bem como as reflexões de suas ações cotidianas mobilizadas pelos acontecimentos gerados nos espaços-tempo desta investigação.

Por tudo isto, acreditamos que este texto indica um caminho promissor para outras investigações que visem analisar processos grupais, nos quais os participantes estejam implicados em fazer acontecer propostas instituintes/inovadoras na Saúde Coletiva, que sabemos constituir um campo que se constrói cotidianamente a partir de lutas constantes e permanentes desafios.

\section{Referências}

AGUIAR, K. F.; ROCHA, M. L. Micropolítica e o exercício da pesquisa-intervenção: referenciais e dispositivos em análise. Psicologia: Ciência e Profissão, [Online] v.27, n.4, 2007, p.648-663.

ARDOINO, J; LOURAU, R. As pedagogias institucionais. São Carlos: Rima, 2003.

BARROS.; R. B. Grupo a afirmação de um simulacro. Porto Alegre: Sulinas/Editora da UFRGS, 2007.350p. 
BARBIER, R. A pesquisa-ação. Brasília: Plano Editora, 2002. 159p.

BAREMBLITT, G. Compêndio de Análise Institucional e outras correntes: teoria e prática. $5^{\text {a }}$ ed. Belo Horizonte-MG: Instituto Felix Guattari, 2002.

BOTAZZO, C. Da Arte Dentária. São Paulo: HUCITEC: FAPESP, 2000.

BOTAZZO, C. Sobre a bucalidade: notas para a pesquisa e contribuição ao debate. Ciência \& Saúde Coletiva, Rio de Janeiro, v.11, n.1, 2006, p.o717; 39-43.

BOTAZZO, C. et al. Saúde bucal coletiva. São Paulo, 1988. 14p. (Elaborado como material de apoio ao Curso para Formação de Técnico em Higiene Dental, do SUDS-SP)

CAMPOS, G.S.W. Saúde Paidéia. São Paulo: HUCITEC, 2003. 185p.

CAMPOS, G.S. W. Um método de análise e cogestão de coletivos. 2. ed. São Paulo: Hucitec, 2005. 236p.

EL ANDALOUSSI, K. Pesquisas-ações: ciências, desenvolvimento, democracia. São Carlos: EdUFSCar, 2004.

FONSECA, T. M. G. et al. Pesquisa e acontecimento: o toque no impensado. Psicologia em Estudos, v.11, n.3, 2006, p.655-66o.

GUATTARI, F. A transversalidade. In: GUATTARI, F. Revolução molecular: pulsações políticas do desejo. 3. ed. São Paulo: Brasiliense, 1987. p. 88105.

HESS, R. Uma técnica de formação e de intervenção: o diário institucional. In: HESS, R.; SAVOYE, A. (Coord.). Perspectives de l'analyse institutionnelle. Paris: Méridiens Klincksieck, (Tradução: Ana Lúcia A. da Silva e Lucia C. Mourão. Revisão: Solange L’Abbate), 1998. p.119138.

HESS, R. Momento do diário e diário dos momentos. In: SOUZA, E. C.; ABRAHÃO, M. H. M. B. (Orgs.). Tempos, narrativas e ficções: a invenção de si. Porto Alegre: EDIPUCRS, 2006, p.89-103.
HESS, R.; SAVOYE, A. L'analyse institutionnelle. 2. ed. Paris: PUF, 1993.

L'ABBATE, S. A análise institucional e a saúde coletiva. Ciência \& Saúde Coletiva, v.8, n.1, 2003, p.265-274.

L'ABBATE, S. Intervenção e Pesquisa Qualitativa em Análise Institucional. In.: BARROS, N. F.; CECATTI, J.G.; TURATO, E.R. (Org.) Pesquisa Qualitativa em Saúde: múltiplos Olhares. Faculdade de Ciências Médicas/UNICAMP, Campinas-SP, 2005. p.235-246.

LOURAU, R. A Análise Institucional. $1^{\mathrm{a}}$ ed, Petrópolis: Vozes, 1975. 294p.

LOURAU, R. Sociólogo em Tempo Inteiro. Análise Institucional e Pedagogia. Lisboa: Editorial Estampa, 1979. 315p.

LOURAU, R. Le lapsus des intellectuels. Toulouse : Privat, 1981. 293p.

LOURAU, R. Le journal de recherche. Paris : Méridiens Klincksieck, 1988. 271p.

LOURAU, R. René Lourau na UERJ- 1993. Análise Institucional e Práticas de Pesquisa. Rio de Janeiro: Editora da UERJ, 1993. Mnemosine. Vol.3, $\mathrm{n}^{0}{ }_{2}$, 2007. Disponível em: <http://www. mnemosine.cjb.net/mnemo/index.php/mnemo/ issue/view/20> Acesso em 22 ago. 2008.

LOURAU, R. 0 instituinte contra o instituído. In: ALTOÉ, S. (Org.) René Lourau. Analista Institucional em tempo integral. São Paulo: Hucitec, 2004a, p.47-65.

LOURAU, R. Objeto e Método da Análise Institucional. In.: ALTOÉ, S. (Org.) Op cit, 2004b, p.66-86.

LOURAU, R. Implicação e Sobreimplicação. In: ALTOÉ, S. (Org.) Op cit, 2004c, p.186-198.

MONCEAU, G. Transformar as práticas para conhecê-las: pesquisa ação e profissionalização docente. Educação e Pesquisa, v.31, n.3, 2005, p.467-482.

NARVAI, P. C. Odontologia e Saúde Coletiva. São Paulo: Hucitec, 1994. 113p. 
PASSOS, E.; BARROS, R. B. A Construção do Plano da Clínica e o Conceito de Transdisciplinaridade. Psicologia: Teoria e Pesquisa, v.16, n.1, 200o, p.7179.

PAULON, S. M. A análise de implicação como ferramenta na pesquisa-intervenção. Psicologia \& Sociedade, v.17, n.3, 2005, p.18-25.

PEREIRA, E. M. A. Professor como pesquisador: o enfoque da pesquisa-ação na prática docente. In: GERALDI, C.M.G.; FIORENTINI, D.; PEREIRA, E.M.A. (Orgs.). Cartografias do trabalho docente: professor(a)-pesquisador(a). Campinas, SP: Mercado de Letras: Associação de Leitura do Brasil - ALB. 1998, p.153-181.

PEZZATO, L. M. Encontros, Instituições e Sujeitos em análise: A Alta Pactuada em Saúde Bucal. 2009. Tese (Doutorado em Saúde Coletiva) Faculdade de Ciências Médicas, Universidade Estadual de Campinas, Campinas-SP, 2009.
ROCHA, M. L.; AGUIAR, K. F. Pesquisa-intervenção e a produção de novas análises. Psicologia: ciência e profissão. [online] v.23, n.4, 2003, p.64-73.

RODRIGUES, H. B. C.; BARROS, R. D. B.

Socioanalyse et pratiques groupales au Brésil: un mariage hétérogène. L'Homme et la société. No.147-148, p.55-70, 2003/1-2.

THIOLLENT, M. Metodologia da pesquisa-ação. 14. ed. aum. São Paulo: Cortez, 2005.

TRIPP, D. Pesquisa-ação: uma introdução metodológica. Educação e Pesquisa, v.31, n.3, 2005, p.443-466. 